\title{
'Everywhere is becoming the same'? labour utilisation, regulation and the tensions inherent in transnational IT production
}

\author{
Nicole Mayer-Ahuja and Patrick Feuerstein
}

\author{
Nicole Mayer-Ahuja is a Senior Researcher at the Sociological \\ Research Institute (SOFI) at the University of Goettingen, \\ Germany. \\ Patrick Feuerstein is a Researcher and PhD candidate at the \\ Sociological Research Institute (SOFI) at the University of \\ Goettingen, Germany.
}

\begin{abstract}
Does the internationalisation of economic activities reduce the differences between locations in core and peripheral regions of capitalist production? This article contributes to this discussion by emphasising an inherent contradiction of transnational production: companies must draw upon divergent regulatory scenarios and strategies of labour utilisation and articulate them in their organisational structures in order to utilise 'locational advantages' and meet profit targets, but the integration of these divergent scenarios creates considerable organisational tensions. This scenario is illustrated through an analysis of the high attrition rates produced in the South Indian IT hub of Bangalore and how this is managed by one German software production company.
\end{abstract}

\section{Introduction}

In his monograph 'Global Shift', Peter Dicken points to a widespread belief in the homogenising impact of economic internationalisation. According to him, so-called 'hyper globalists' currently represent the 'largest body of opinion', arguing that we live in a borderless world in which the 'national' is no longer relevant. In such a world, 'globalization' is the new economic (as well as political and cultural) order. It is a world where nation-states are no longer significant actors or meaningful economic units and in which consumer tastes and cultures are homogenized and satisfied through the provision of standardized global products created by global corporations with no allegiance to place or community. Thus, the 'global' is claimed to be the natural order, an inevitable state of affairs, in which time-space has been compressed, the 'end of geography' has arrived and everywhere is becoming the same (Dicken, 2007:5).

Since "[transnational] corporations are the primary movers and shapers of the global economy ' (Dicken, 2007:439), their organisational structures are often regarded as transmitters of worldwide homogenisation, not least by many of their employees 
in peripheral locations. An Indian manager, for instance, expressed his hope that the German software company for which he works in Bangalore would soon start to promote Indian managers directly from India to the highest corporate ranks. In his opinion, this would be 'the last step to become a completely global company' (2007:37). ${ }^{1}$ This reveals some disappointment with the Indian subsidiary's current situation by this interviewee who clearly hopes for a homogenisation of work quality and career prospects in the near future.

At the same time, the transnationalisation of production seems to involve deepseated organisational problems. In the IT-sector, for instance, offshoring (defined as the relocation of tasks and workplaces to distant regions outside Europe and the USA) ${ }^{2}$ may well represent a logical consequence of increasing internationalisation (Boes \& Schwemmle, 2005). Nevertheless, managers tend to emphasise that the relocation of high-skilled services may be associated with indirect costs and risks that often outweigh advantages (Vogel, 2005).

In this paper it is argued that the marked difference between the high-flying aspirations of 'hyper globalists' and employees in peripheral offshoring locations, as well as the scepticism prevalent among the management of many parent companies, points to an inherent contradiction of transnational production, in and beyond the IT-sector. On the one hand, transnational production needs to link very different locations in order to utilise their specific advantages and ensure that profit margins are sustained; on the other hand, their articulation within any given company structure creates considerable organisational tensions and conflict which may well reduce productivity. In the case of IT offshoring to locations like India, this contradiction becomes especially clear. If IT companies from the centres of capitalist production employ workers from peripheral 'low-cost regions', it is often not sufficient to establish 'extended work benches'. Companies performing project work or even 'distributed development' between various (peripheral as well as core) locations tend over time o relocate increasingly high-skill tasks to subsidiaries in places like India, since a 'hard' division of labour is usually not possible and an 'upgrading' of working tasks is considered a means of binding individual expertise to an organisation (Hirschfeld, 2004:55-56). As Béret and others (2003) have pointed out, such transnational forms of $\mathrm{R} \& \mathrm{D}$ organisation tend to standardise even strategies of 'human resource management', which often vary markedly across locations (Béret et al, 2003).

In the case of IT companies, which generally present themselves as 'global enterprises' with all-encompassing structures and processes, it is hardly surprising that a worldwide uniformity of labour utilisation practices is claimed - even though these companies need to stretch their organisational structure to encompass very different locations, and have to articulate them through specific arrangements. Bangalore as an

1 'We don't have to move to Germany to become a global ... manager. It should be from India to ... Why should we move to become something ...? It's like ... it's the same thing. There are colleagues, who moved from India to become assistant in the board [...]. So [they] had to move. But the position should be given to people in India, so that they can ...That is the last step to become a completely global company' (2007:31). 2 According to this definition, 'offshoring' does not have to go along with 'outsourcing', i.e. with a transfer of company functions to other companies or business partners. Instead, offshoring can imply either offshore outsourcing or captive offshoring. The latter implies setting up internally-owned production centres in far-away world regions, as was the case in our sample companies (see below). 
'IT location', however, is not only characterised by comparatively low salary levels, it is also shaped by its own regulatory scenario, in which the production and reproduction of labour power follows specific rules, moulded and remoulded by a complex mixture of economic, political and social structures and processes of regulation. ${ }^{3}$ It is one outcome of this regulatory scenario that low salaries are accompanied by a marked lack of employment stability and high rates of attrition (turnover), which shape the regional labour market. ${ }^{4}$ The latter are often identified as one of the most problematic aspects of IT offshoring: they are argued to reduce 'efficiency', for instance, because the continuous loss of knowledge jeopardises quality standards and impedes communication (Hirschfeld, 2004:54-55).

This perspective on the inherent tensions of transnational production lies at the heart of an approach that differs markedly from the identification of 'varieties of capitalism, which focuses on corporate embeddedness in different political economic structures (Hall \& Soskice, 2001) or from a focus 'welfare state regimes' with reference to the political regulation of labour markets (Esping-Andersen, 1990). Instead of analysing distinct 'models' and emphasising their seemingly parallel and congruent development, it is argued here that different regulatory scenarios are increasingly linked through the operations of transnational companies. These corporations need to organise production between different regulatory scenarios, but also within them - and while this constitutes a source of profit, it may simultaneously limit productivity. ${ }^{6}$

In this paper, this contradiction is highlighted by focusing on one specific case of transnational production: the operations of a German IT company in the South Indian city of Bangalore. This company's corporate standards of labour utilisation, with their focus on long term company affiliation, have been shaped in the context of the German 'coordinated market economy', in which stable (male) employment is supported by a 'conservative welfare state' and by a lack of job alternatives in years of relatively high unemployment. In Bangalore, this company tries to keep up these standards, although it operates in the context of an economy shaped by the rapid transition (since 1991) from postcolonial 'protectionism' to a new regime heavily influenced by Anglo-Saxon standards (generally characterised as 'liberal' market economies and welfare states) with stiff competition for 'scarce talent' especially from 'home grown' Indian service companies.

In the second section, the regulatory scenario confronting the German product company in Bangalore is outlined briefly. Special emphasis is placed on how the high

3 For a similar conceptual approach to regulatory 'fields of force' see: Pries, 2005.

$4 \quad$ In India, industry experts, company representatives and social scientists would use the term 'attrition' rather than the term 'turnover' when referring to the quota of leaving staff. Our terminology is borrowed from them.

$5 \quad$ Meta Group 2004 (cited in Vogel, 2005:15) stated that Offshoring was likely to reduce 'efficiency' by up to 20 per cent; 1 -2 per cent is explicitly attributed to attrition.

6 This paper constitutes the first attempt to test this approach. It is mainly informed by the authors' empirical research so far, but will be further conceptualised in two monographs currently under preparation. Research has been conducted since May 2006. The sample contains around 25 interviews with experts on IT development in Germany and India, and roughly 80 interviews with managers and employees of six firms, including German product companies and Indian service companies. Intensive case studies were conducted in one German product company and one Indian service company, focusing on Indo-German project teams cooperating between both companies' home bases and foreign subsidiaries. This article draws mainly on these case studies. 
attrition rates prevalent in this urban region's labour market are produced. This can arguably be traced back to a specific breadwinner model, but is also related to state influence and an economic environment that differs considerably from the setting of the German home base.

The third section focuses on this company's efforts to cope with high attrition rates. It will be argued that some adaptation to the characteristics of Bangalore's IT labour market can be observed, alongside a tendency to approximate to the German mother company's standards. Instead of homogenisation between the two locations, what we are witnessing is the emergence of a new and very specific strategy of labour utilisation in the Indian subsidiary that questions established features of intra-organisational coordination. Thus, conflicts within transnational project teams emerge. Discussed as a 'clash of cultures' in many interviews, such crises arguably reflect the inherent contradictions of transnational production to which we will now turn.

\section{The production of attrition - approaching labour market regulation in Bangalore}

According to our hypothesis, companies from capitalist core countries operate in 'low cost locations' to increase profits but at the same time face problems articulating very different regulatory scenarios within their organisational structures. What is so different about the regulatory scenario in Bangalore that it could potentially jeopardise intra-organisational homogenisation? We will focus here on one aspect of this problem, the production of high attrition rates, in order to gain a first insight into the complex regulatory context in which the German company has to operate in India.

Before turning to the reason why this is such an important issue in Bangalore, the phenomenon of 'attrition' needs to be unpacked. Even if the definition is tightened to include only voluntary attrition (when employees leave of their own accord) rather than broadening it to include all the employees who leave a company in the course of any given year (Upadhya \& Vasavi 2006:50), it is still necessary to distinguish between 'exit attrition' (when employees leave the IT sector for good) and job changes that take place within the IT sector, which can include both horizontal attrition (when employees move between similar companies) and vertical attrition (when employees move between different types of company, for instance between service and product companies).

'Exit attrition' illustrates the extent to which corporate labour utilisation strategies have to take account of the social practices that are prevalent in Indian society in general and more specifically among the Indian middle classes who make up the majority of the workforce in Bangalore's IT companies. ${ }^{7}$ These social practices are very different from those in Germany, as can be illustrated, for instance, by the concept of 'life long employment'. In Germany, even in IT related occupations, (MayerAhuja, 2006), it has become increasingly common to opt for 'stable' careers, ideally by committing to one company, as expressed in the German notion of 'standard employment' (Mückenberger, 1985). Even the number of 'family breaks' taken by women has reduced considerably over recent decades. Instead of leaving paid

$7 \quad$ According to recent studies (Krishna \& Brihmadesam, 2006; Upadhya, 2007) the majority of IT professionals have an urban, high-caste and middle-class background. 
employment at the age of 25 and returning, if at all, to less qualified jobs around the age of 40, which was quite common in the 1950s, women in Germany today tend to return to their jobs as soon as possible after their children are born (Mayer-Ahuja, 2003:58-59).

In India, by contrast, paid employment is still not accepted as a life-long prospect for women in many middle-class families. Although there seems to be an emerging tendency among some female interviewees to minimise their 'family breaks', many women still leave the IT industry for good in their mid twenties, when they get married or have children. Of course, these social differences cannot be understood without reference to a lack of 'family-friendly' employment options (such as part-time work or telework) in many IT companies, and state policies that have failed to provide sufficient public child care or parental leave schemes ${ }^{8}$. However, corporate labour utilisation strategies have to take account of the fact that many women (who often represent 20 to 30 per cent of staff in Indian IT companies) may quit their jobs after only a few years of employment. This means that the companies have to make distinctions between German and Indian women.

Secondly, IT companies operating in Bangalore are faced with a scope of political regulation, far exceeding German standards. Even the persistence of high attrition rates ${ }^{9}$ is, arguably, a result of long-term state policies, at least to some extent. After all, the very development of the Indian IT industry was supported directly by the Indian government ${ }^{10}$ (Lema \& Hesbjerg, 2003:11; Heeks, 1996:3366). Government policy played an even more important role in the sector's massive regional concentration, which creates an environment that facilitates frequent job changes, as also happens in the Silicon Valley IT hub (Fallick et al, 2005:3). It was the central government's import substitution policy (from 1947 to the mid-1980s), for instance, that enabled Indian IT companies to develop within a well-protected environment. Technical education was promoted by founding 'Indian Institutes of Technology' as state-owned elite institutions. A ban on foreign companies' setting up shop in India resulted in 'body-shopping' arrangements whereby Indian IT staff were shipped abroad to work on the premises of client companies, especially to the US (Lateef, 1999:chapter 2.4). After 1990, however, IT production within India was promoted and foreign companies were attracted by granting them 'tax holidays', free infrastructure or the permission to expatriate profits from 'Software Technology Parks' (Heeks, 1996:142). Bangalore ${ }^{11}$ had been turning into a centre for public (especially military) research and development since the 1950s, which may explain its high literacy rates (Heitzman, 2004:220) and the impressive number of science graduates. ${ }^{12}$ Moreover, the State of Karnataka offers special incentives to foreign

8 The Indian 'Maternity Benefit Act \& Rules' only entitles young mothers to a period of maternity leave of 84 days around the time of delivery (plus 30 days in case of poor health).

9 In fact, attrition rates have fluctuated, reaching a peak of 25 per cent in 1999-2000, when the preparation of software for the start of the new millennium boosted employment (Upadhya \& Vasavi, 2006:50-51). 10 This refers to the Central Government of India, the State Government of Karnataka and the City Government of Bangalore.

11 Of the top 200 software companies, 68 were located in Mumbai, 56 in Bangalore and 30 in Delhi in 1995 (Nasscom 1995:19, quoted in Lateef, 1999, chapter 2.4).

12 By 1995, Karnataka hosted over 17,000 engineering students. In 2000, there were 82 reputable 
companies to locate in Bangalore, from assistance in acquiring land ${ }^{13}$ to direct financial subsidies ${ }^{14}$.

It can even be argued that the massive agglomeration of IT in cities like Bangalore has resulted from political regulation by more than one nation state, since the take-off of IT production in India around 1990 concurred with the tightening of US immigration rules (Lateef, 1999, chapter 2.4), motivating many Indian professionals to seek jobs 'at home'15. In our case study, German visa regulations also played a crucial role, by influencing the emphasis put on Indian employees' presence in Germany and thus their capacities to build professional networks within their company. The impact of state policies contradicts the 'zero sum' conception of spatial scale, according to which 'state scale is said to contract as the global scale expands', for instance, by way of transnational company operations (Brenner, 1998:3). In the case of the Indian IT sector, which exported 78 per cent of its products and services in 2006 (Nasscom 2007) and has been described as a 'virtual extension to leading technology firms and regions in the OECD countries' (Lema \& Hesbjerg, 2003, xii), even state regulation has thus acquired transnational features.

Even though the Indian government's support for IT development has arguably benefited Indian as well as non-Indian companies, the omnipresence of political regulation causes problems, especially for foreign firms. The Indian government's recent turn ${ }^{16}$ to an active 'privatisation of standard setting' has transferred a number of regulatory activities to non-state actors, particularly favouring representatives of the big Indian IT companies. Having partly emerged from the Bangalore context and being well connected to political decision makers, these companies have acquired remarkable regulatory influence. This is evident in initiatives like the 'Bangalore Agenda Task Force' (1999-2003), which assembled representatives of Karnataka State, Indian corporate leaders (mainly from IT companies) and members of 'civil society' in order to tackle the city's deterioration in the wake of the IT boom. Celebrated for its achievements by some (Sukumar, 2003), it was rigorously criticised by others for its tendency to address only topics (like land development, water, telecommunication or traffic management) closely related to the 'businesses and private lives' of the middle classes (Ghosh, 2005:4916). Through such initiatives, Indian companies have successfully strengthened the IT cluster in which they operate and adapted the city's economic structure to fit corporate needs. Both Indian and foreign companies profit from development, although such infrastructural improvements attract more and more competitors for scarce talent and boost attrition even further. It is increasingly the big Indian firms, however, that shape the conditions of operation in 'location Bangalore' with which every other IT company has to comply.

engineering colleges, increasingly concentrating on electronic engineering and IT (Heitzman, 2006:222-224). 13 The 'Land Acquisition Act' (1894) entitles the state to claim land for 'public use'. According to an expert from a Bangalore-based NGO, agricultural land was usually bought by the state below market price and (semi-legally) converted into land for non-agricultural use and then sold to IT companies at the same reduced rate. 14 For instance, IT companies are charged industrial tariffs instead of (higher) commercial tariffs (IT Secretary of Karnataka, 2007).

15 Indian IT professionals working for US clients on H1B visas now had to be paid according to the prevailing US wages and taxed on their US income.

16 This constitutes a break with the Indian tradition of regulating labour markets directly (at least in the formal sector), for instance, by establishing minimum wages or legal labour standards. 
Thirdly, the German software product company in our sample operates within a specific sphere of economic regulation in Bangalore, which is strongly shaped by conflicting corporate strategies. As far as 'attrition management' is concerned, the IT industry has started to harmonise remuneration, in order to reduce the notorious practice of 'job hopping for a few rupees' ${ }^{17}$, but this has not stopped individual companies from engaging in strategies of labour utilisation that continue to boost attrition. For example the biggest IT companies provide detailed information about their (allegedly confidential) salary structures to consultancies (like Hewitt), who collect and publish the data. Access to this information is restricted by massive fees, supposed to ensure that only companies, not employees, learn about income trends.

Currently, this fragile regulatory system is frequently undermined. IT companies still recruit their competitors' staff by way of offering (slightly) higher salaries and IT professionals are well informed about salary levels in different companies since they discuss their earnings with relatives, friends, colleagues or former college mates or even publish them on matchmaking websites in order to attract potential spouses (or their parents). Under these conditions, outsiders like our German case study company might find it difficult to determine salary levels since, although they can buy consultancy data, they have inferior access to the IT sector's informal networks. Moreover, they are confronted with a scope of 'job hopping' unknown in Germany, where jobs are usually not changed 'for a few euros', although there is, in principle, scope for individual wage bargaining in Germany because of the lack of collective agreements in most of the German IT sector.

On the other hand, all efforts to tackle attrition collectively are undermined by the strategies of investment, recruitment, and work organisation adopted by many IT companies. Even if an individual firm (like our German example) decides to opt for greater employment stability to catch up with the standards in Germany, it is difficult to counteract the general trends in the local labour market in which the dominant influence is the Indian service companies ${ }^{18}$, whose practices have a strong influence on the qualifications, work attitudes and career expectations of the regional IT population. These companies employ tens of thousands of employees in their Bangalore production centres alone and recruit vast numbers of college graduates each year. In these companies typical staff turnover is well over ten per cent per annum (Nasscom, 2005), but their typical reaction to these high attrition rates is an attempt to 'standardise resources'19 in order to reduce companies' dependence on individual employees. It is hard to determine whether this attempt has been successful: managers tend to claim it has, pointing to process models and 'knowledge management' ${ }^{20}$, whereas IT professionals say that it still takes several weeks for their colleagues to be able to substitute for the work of someone who has left the company (for a more detailed account see: Mayer-Ahuja \& Feuerstein, 2007).

Notwithstanding these limitations, the efforts by Indian service companies to standardise their processes have already had an enormous impact on the IT labour

17 This expression is used by many management representatives and industry experts.

18 The most successful Indian service companies include TCS, Infosys, Wipro, Satyam and HCL.

19 'Resource' is understood here as a unit of measurement for labour power, including the performance and qualifications of an 'average employee'

For a critical view of the implications of Knowledge Management, see McKinlay, 2005. 
market in Bangalore. Firstly, standardised job descriptions, which aim to adjust individual labour power to a predefined 'average' knowledge, experience and level of performance, inevitably boost attrition: these descriptions may render it easier for companies to replace leaving employees, but they also make it much easier for IT professionals to move to competing firms. Secondly, Indian service companies more or less shape the skill set of the 'average' IT professional, since thousands of college graduates from all streams of engineering are provided with basic IT knowledge in their corporate training courses each year. Finally, employees' expectations of 'good' IT work are thoroughly influenced by the standards of labour utilisation prevalent in these Indian service companies.

The primary attraction of an IT job is often not the quality of work, but 'the career one can have or the money one can earn' (Upadhya \& Vasavi, 2006:54-55). Work in these companies is dominated by business process involving the updating of old technologies and systems for Western customers, characterised by task fragmentation in the wake of standardisation and elaborated systems of direct and technical control, which are required to maintain high standards of cost, timeliness and quality (as demanded by customers and guaranteed by certifications such as CMM). Whether or not this is 'mimicking [...] the old Taylorist system of factory management' (Upadhya \& Vasavi, 2006:65), it is quite obvious that 'typical IT work' has acquired some specific features in the Bangalore context. These features are not uncontested, however. Many developers complain about routine and monotonous work (Upadhya \& Vasavi, 2006:66) and constant attempts to 'improve their marketability' have arguably contributed to the development of a vicious circle whereby high attrition rates create a situation where companies are not as 'willing to invest in any one employee, given the pattern of attrition'. The result has been a

Catch-22-situation, in which employees begin to feel dissatisfied when their jobs or projects do not allow them to improve their knowledge, while companies are reluctant to invest too much in employees who may not stick to the job. (Upadhya \& Vasavi, 2006:55).

Under these conditions, the adaptation of foreign IT companies to the Bangalore IT labour market seems to have (at least) two aspects: on the one hand, foreign companies with a reputation for offering less standardised and more challenging work can recruit employees with an above-average technical interest, who are especially frustrated with the job profiles prevalent in Indian service companies. On the other hand, even foreign companies seem to feel a need to experiment with strategies of short-term labour utilisation as perfected by their Indian competitors. Especially in Western product companies, attrition rates are generally lower than in Indian service companies (Upadhya \& Vasavi, 2006:53). However, these companies still draw upon the same IT workforce, which encompasses a large group of workers with relatively fragmented qualifications, hardly any emotional attachment to a specific company, and high preferences for fast promotion and rising incomes. Thus many foreign firms, which are often not regarded as 'permanent employers' (since they might move their production centres at any time), do not seem to these Indian workers to be offering sufficient opportunities for formal promotion, upgrading of 
skills or career options within their organisational structures that could bind their especially ambitious employees.

Moreover, recruiting from a competitors' workforce (rather than training their own staff) seems to be an integral part of many Western companies' employment strategies. Under these conditions, high rates of attrition can be argued to be the results of attempts by sought-after IT professional to build stable careers in a situation where the job options are highly unstable:

While the industry desires a workforce that is mobile and flexible, this requirement has also created a culture of individualism in which employees pursue their own goals over those of their employers - who are in any case often temporary. (Upadhya \& Vasavi, 2006:48)

It is necessary to bear this complex regulatory scenario in mind when analysing the management of attrition by our German case study company in Bangalore, because its strategy of labour utilisation has to take into account the social practices prevalent among the Indian middle classes, including a gendered breadwinner model, as well as the career-building strategies of IT professionals who try to increase their individual knowledge and experience in order to secure their career prospects in a highly unpredictable labour market. The high attrition rates this company has to cope with can also be seen as a result of long-term state policies developed to promote the emergence and massive regional concentration of the (Indian as well as foreign) IT industry in Bangalore and the transfer of regulatory activities to private parties which has favoured Indian IT companies. Finally, the German company needs to compete for 'talent' within a corporate 'IT scene', within the terms of a strategy that attempts to restrict attrition by means of 'collective standard setting', but boosts it at the same time. While the big Indian service companies tend to promote the IT cluster in Bangalore and support job hopping through standardisation, many foreign companies seem to rely on short-term investments and continuous poaching rather than offering qualifications and long-term prospects to their employees.

\section{Managing attrition in a German product company}

This very rough sketch of the conditions of operation for our German product company in the 'low cost location' of Bangalore has emphasised that high rates of attrition constitute an integral part of this regulatory scenario, are deeply rooted in social practices and are further promoted by state policies and corporate strategies of labour utilisation. The approaches of the big Indian service companies are of primary importance for the functioning of the regional labour market since they shape the skill requirements, work attitudes and career expectations of a considerable part of the regional IT workforce. In this paper we therefore also draw on our interviews in an Indian service company, for purposes of comparison.

What kind of company are we looking at then, and how can its strategy of labour utilisation (and especially of 'attrition management') in the Bangalore context be characterised? At a first glance, it could be argued that this German product firm has been quite successful in transferring standards of employment stability from its home base. After all, the annual rate of attrition has 'only' reached between 6 and 9 per cent 
over recent years (compared to 14 per cent in 2006-7 in the Indian service company we studied). Hence it is not uncommon to meet employees with more than five years experience in the company affiliation here, whereas employees in the Indian service company tended to leave after two to three years. ${ }^{21}$

In the case of our German company, the lower attrition rates seem to stem from the higher quality of the work experienced by employees of this production unit in comparison with those of nearby service companies, bolstered by the fact that the case study company, which conducts research and development in different locations across the globe, ${ }^{22}$ had considerably strengthened the position of its subsidiary in Bangalore since its foundation around $1999^{23}$. A leading management representative explained that this strategy was driven by the desire to draw upon the Indian talent pool, which was a common reason for 'offshoring' during the late 1990s when there was a shortage of IT skills in Europe and the US (Hirschfeld 2004, 29). It may not be fully coincidental, though, that the Indian subsidiary was expanded during the general downturn in IT production (after 2001) at a time when the company was increasing its efforts to raise productivity and keep product prices low. The position of the company's products in the market was being challenged, profit margins had shrunk and a strategy was developed of targeting new customer groups with specific budget restraints. There is, thus, good reason to conclude that the expansion of the production centre in Bangalore was part of an attempt to secure profitability by means of a strategy of drawing on 'low cost locations'. According to our hypothesis, the consequent need to articulate different scenarios of regulation within a single organisational structure was likely to generate considerable intra-organisational tensions. The results are differential strategies of labour utilisation, rather than a homogenisation between core and peripheral locations.

In order to characterise this company's strategy of labour utilisation in Bangalore we need to analyse the complex interplay between regional adaptation and adaptation to the standards of the German home base, characterised by employment stability, flat hierarchies and a relatively low level of (task and process) standardisation. As far as attrition management is concerned, adaptation to the Bangalorian labour market seems to entail a rather typical mixture of strategies - aimed simultaneously at restricting attrition and 'channelling' it - which can also be observed in Indian service companies. The company's strategies for 'binding' employees to their jobs, for example, are mostly borrowed from the Indian 'competitors for talent', although applied on a much smaller scale. The German company's offices, for instance, are modern, architecturally attractive, and well-maintained, offering employees a chance to escape from the city's heat, dust and noise in their immediate work environment. These premises include

21 Such attrition data are not fully reliable: alarmist voices often claim annual turnover rates of 25-30 per cent for certain companies, but industry representatives often quote surprisingly low figures. Additionally, attrition rates may vary within an organisation.

22 Interviews were conducted in different teams within one department in charge of developing parts of a new standard software package. The rest of the software is developed in different locations all over the world, with a certain dominance of the German home base. Within this department, sub-units deal with different functionalities of the module.

23 In 2007, 36 per cent of the total staff worked in Germany, whereas the Indian subsidiary was home to 7 per cent. 
recreational facilities, like a gym and a canteen, ${ }^{24}$ but lack the swimming pools and golf courses maintained by some Indian companies. This is probably because of the smaller number of employees who work at the company's Bangalore site (less than five thousand, compared with the tens of thousands who may be employed in some of the Indian service companies). In general, the whole setting is less spacious and splendid than in Indian counterparts. As a result, the employees do not tend to spend their free time on the company premises, as is often the case in some Indian service companies, and social events are less frequent. The atmosphere is quieter and more work-focused, which might also be related to the higher average age of staff. This is in turn linked with the German product company's strategy of recruiting experienced IT professionals, rather than 'freshers' in their early twenties, who usually do not have everyday family obligations and stay on the campus even after long working hours. However, just like Indian service companies, this German company does hold competitions (for the employee or team of the month), which would be hard to imagine at the German home base. Asked about the advantages of working for this company, however, most interviewees emphasised the chance to work with interesting technologies and exercise individual responsibilities rather than any advantages of work environment or campus.

Moreover, the scale and development of salaries indicates that this German product company has neither fully adapted to the local regulatory scenario nor completely transferred the standards of its home base. In the Indian IT sector, incomes have increased annually by more than ten per cent during the last few years, ${ }^{25}$ and the average salary of our interviewees (below management level) amounted to between 30,000 and 40,000 rupees (equivalent to approximately 550 to 735 euro) per month in 2007 . However, there are still marked differences between the German product company and local Indian service providers. In one Indian service company, employees at entry level would be paid around 10-15,000 rupees (approximately 180-280 euros) per month. Fast promotions render it possible, however, to reach gross salaries of 55,000 rupees (1,000 euro) after two to four years (or one to two promotions), ${ }^{26}$ and frequent postings to client sites in Europe or the USA are an additional source of income.

In the German product company, by contrasts, entry level pay is much higher, ranging from 30,000 rupees (550 euro) to 45,000 rupees (830 euro) per month in the first year. This sum is additionally increased by one-off bonuses (40,000 rupees or 740 euro in 2006). After five or six years in the company, an employee's salary will roughly double. This marked difference in basic salaries may explain the widespread assumption that a change from a service to a product company can inflate earnings by 25 to 30 per cent. On the other hand, this German product company hardly offers any postings to Europe or to the USA, which are usually rewarded with a considerable onsite bonus in service companies, and promotions are less frequent. This makes it hard to determine which company 'pays better' in the end.

24 There is only one canteen, however, providing free Indian food during lunchtime, and employees go for quick lunch breaks, as would be common in any typical German company. This is a marked contrast to the Indian service company of our sample, where several facilities offer a much wider choice between styles and tastes and food can be purchased throughout the day.

25 According to Nasscom (2007), average IT salaries in India increased by 15 per cent in 2006.

26 These figures include variable parts of the salary. 
In any case, it is obvious that the need to articulate the Bangalorian regulatory scenario within this German product company's organisational structure calls the 'low cost' strategy of labour utilisation into question: salaries are considerably lower than in Germany, but they have still needed to rise much faster during the last few years than at the company's home base in order to attract Indian employees with sufficient qualifications and experience. Some German employees we interviewed expressed fears that the Indian competitors might be catching up faster then expected, at least in monetary terms. At the same time, Indian employees find it hard to accept that their friends and contemporaries are receiving much more rapid salary increases in other IT companies in Bangalore. Decisions about pay increases are taken in Germany and thus partly influenced by the context of a stagnating labour market at the company's home base.

This is not the only source of tension between 'Indian' and 'German' standards, however. As could be expected in an environment shaped by the efforts of the big Indian service companies to 'channel attrition' by reducing dependency on individual employees (Mayer-Ahuja \& Feuerstein 2007), the effects of standardisation and the quality of work are also contested. In general, the expectation that the quality of work is higher in product than in service firms seems to be met in our German sample company. Here, the Indian subsidiary is developing parts of a new product, which many interviewees consider the most attractive type of IT work because it implies challenging tasks, involvement with the latest technologies and a high 'visibility' of one's own contribution with management. Since, unlike in a service company, there is no direct customer involvement (because the work is commissioned by another department within the same company), developers have in the past been shielded from the strong external pressures that are omnipresent in service companies.

Currently, under conditions of increasing competition, however, this is beginning to change as new business processes are being tested, including a closer monitoring of cost, time and quality, although tasks are still less standardised, and thus more satisfying for employees, than in the Indian service company of our sample. Apart from certain basic process descriptions and coding styles, there are considerably fewer process models or mandatory process descriptions, and existing standards are less strictly followed in the work process. Task distribution usually seems to be discussed in team meetings (rather than dictated by the project manager). Moreover, these tasks are defined in less detail, often require a high amount of individual or collective problem solving, and cover days or even weeks instead of hours. Finally, work processes seem to be even less predictable than in service companies, where customer requirements change frequently. Because software is developed in parallel in different locations across the globe, each individual part is dependent on the progress of other parts, thus increasing the need for communication, cooperation, and also improvisation. As a result, many IT professionals consider process models and especially documentation requirements to be obstacles impeding 'distributed development': if a deadline is approaching and pressure rising, process requirements are regularly skipped in order to finish the job on time. Thus the most important difference between product and service companies is probably not the number 
of 'process descriptions ${ }^{27}$, but the widespread practise of ignoring such formal requirements in the German product company, which seems to be neither monitored nor sanctioned. On the whole, project management seems to rely more on the individual responsibility of team members than on managers' direct or technical control.

The 'standardisation of resources', by way of knowledge management or computerised time and performance tracking, is also pursued with considerably less vigour than in the service companies. Even the term 'resource' is usually not used - instead, even managers refer to employees as 'colleagues', as would be common in the company's German home base. Having said this, it should be noted, though, that the German product company has started to implement certain standards for project management and documentation over the last few years, although compliance is not mandatory yet. Many of these efforts seem to have their roots in the Indian subsidiary, where the attempt to standardise tasks and task performance is a reaction to high attrition rates: they are lower than in service companies, but seem to be even more problematic, since achieving an equal level of productivity after replacing a team member takes around six months (as opposed to three weeks in a service company), according to managers. Hence, it seems that new process models and measures of quality management are often tested in India before they are applied at the company's home base, where opposition to 'standardisation' appears to be more widespread than in Bangalore. It can therefore be argued that the new strategy of labour utilisation emerging in the Indian context is beginning to challenge the established standards of work organisation at the company's home base too, posing a threat not only to their attitudes to work, but also to employees' professional self-perceptions. The emphasis on individual creativity and responsibility that has up till now undepinned work organisation at the German home base is fundamentally challenged by the new standards emerging from 'location Bangalore' which have in turn been shaped by the need to cope with the high attrition rates there.

Another effect of the specific strategy of labour utilisation emerging from the German product company's Bangalore subsidiary can be seen in the development of employment relationships and career paths. In Germany, the relatively high independence granted to developers is implicitly based on their typically long experience in the company, and it can be argued that the staff structure mirrors these standards as well as the changes that are currently taking place. Two factors explain this long average job tenure in the company: in the past, when it was expanding rapidly in Germany, many employees seem to have chosen to remain there because of the relatively high levels of responsibility they were able to exercise there; and more recently, when the IT market stagnated in more recent years, they remained there because of the lack of alternatives.

Setting up the Indian subsidiary was not accompanied by an expansion or a contraction in the German workforce (Hirschfeld 2004:50), but with a stagnation of employment. This means that the German staff is comprised of employees with long-

27 The actual number of process descriptions is recited proudly in the service company (at least by managers), but never mentioned in the product company of our sample. Obviously, none of our interviewees was aware of it or considered it worth communicating. 
term affiliation to the company, who have acquired sufficient knowledge, experience and organisational overview to be able to perform their tasks independently and through self-organised cooperation. In the Bangalore production centre, by contrast, employment relationships are much less stable. Employees do enjoy a relatively high degree of responsibility, but expect fast promotions at the same time, which could only be ensured within a more hierarchical structure. As argued above, many employees' expectations are shaped by the standards of Indian service companies, which offer clearly defined career paths ${ }^{28}$ as well as regular and relatively reliable promotions, usually after no more than two years. Consequently, the long intervals between promotions are the main reason for leaving the German product company in India. Unlike their German colleagues, Indian IT professionals are not content to stay in the position of a 'simple developer' for years, although their work-related responsibility does not (fully) depend on this formal designation. In the Bangalore context, however, formal titles (rather than actual responsibility) seem to determine a worker's social status. It is easier, for instance, for someone who is called a 'project manager' to find a suitable spouse, obtain a mortgage or ensure a place for a child at a 'good' school than it is for someone who is a 'developer', even if the latter works for a reputable company.

Accordingly, the German product company has started to generate new titles and this creates considerable tensions within transnational project teams. While these titles are appreciated by Indian employees, they are ridiculed by their German colleagues, since the titles themselves usually do not imply any significant change in function. Moreover, employees are in fact also promoted slightly faster in India than in Germany, although they still progress much slower than in the average Indian firm. This fuels tensions, for instance, between Indian project managers and German developers, the latter of whom are older, more experienced and in fact functioning as superiors to their more grandly titled Indian colleagues. In this constellation, German developers may well feel left behind, even whilst the Indian project managers are frustrated because their positions are not taken seriously. These problems, which arise from a transnational company's attempt to establish the home base's standards (in this case: flat hierarchies, employment stability and low levels of standardisation) in a different location, point to the inherent contradictions of transnational production mentioned above.

\section{Conclusion}

This brief outline has shown that the operations of our German product company in Bangalore bring into question some of the assumptions both of 'hyper globalists' and of many Indian employees that transnational production will result in a homogenisation between core and peripheral locations of capitalist production. Even in the IT sector, where companies tend to rely on high-skilled work and intensive transnational cooperation within project teams, and claim a worldwide uniformity of labour utilisation practices, they are still confronted with the inherent tensions of transnational production. The German product company in our study, for instance, is forced to

$28 \quad$ A specific set of competencies is related to every role, containing technical and behavioural competencies. Employees are appraised annually with regard to these criteria. If a person matches the requirements and if there is a position available within the organisation, the person can be promoted. Otherwise, necessary skills have to be improved by qualification measures in the respective fields. 
remould its standards to some extent when operating in 'location Bangalore'. Our focus on attrition management has provided a first impression of the conditions of operation in this location, revealing that the company has to articulate within its organisational structure a specific regulatory scenario in this 'low cost location', which comprises a breadwinner model, a scope of state influence and an economic environment that differ markedly from those that characterise the setting of its German home base.

On the other hand, by adapting its strategy of labour utilisation to this regulatory scenario - and, more specifically, to the high attrition rates that prevail there - this company has provoked tensions within its Indo-German project teams, which reflect different and partly incompatible standards of labour utilisation. As already indicated these differences can be observed in the spheres of remuneration, standardisation and intra-organisational promotion. It can be argued that a specific strategy of labour utilisation has emerged in this company's Bangalore location in response to the local situation, which has several key features. Firstly, salaries must be increased and, although they cannot keep pace with raises in other local companies, must nevertheless increase faster than in Germany in order to attract skilled employees. Secondly, standardisation must be promoted in a similar approach to attrition management as that adopted in Indian service companies, but cannot reach the same level as in these companies; a middle ground must be found between the practice of setting targets for tasks over a period of weeks in Germany, to controlling them on an hourly basis in India, requiring additional managerial efforts. Staff must be promoted much faster than at the German home base but still less frequently than is the norm in Bangalore, and so on.

This takes us back to our starting point: to the inherent tensions ingrained in transnational production. Its contradictory nature should have become clear in the course of the argument, but are these tensions really inherent, or is there a way of resolving them? If IT companies from the centres of capitalist production establish subsidiaries in 'low cost locations' can they really homogenise their strategies of labour utilisation? In the case of our German product company, there seem to be two options.

First, the company could insist upon that its Bangalore subsidiary reproduces the home base's standards, even if this is at a lower level. Employees would have to perform less skilled tasks, but could be allowed to work within relatively extended time frames and under limited managerial control; they would be paid at the middle of the range with relatively stable salaries, stay in their positions for quite a long time, and might even gain ownership of certain parts of a product. Unfortunately, it would not be possible to 'bind' IT professionals to the company under the conditions of the booming Bangalore labour market: stable employment, which arguably lies at the heart of the company's strategy of labour utilisation in its home base, simply could not be achieved by such means.

The second option would imply adapting even more closely to the regulatory scenario of Bangalore and especially the need to counteract (in our case) the high local attrition rates. Under this scenario, salaries would have to rise much faster, standardisation would have to be further developed and promotions would have to happen more frequently. If this were to happen, however, the Bangalore subsidiary would cease to function as a 'low cost location' in the long run. In order to ensure 
low salary levels, the company would have to look for other, cheaper locations of production - where it would inevitably face the sames problem of articulating multiple location-specific regulatory scenarios within a single organisational structure.

Obviously, much broader empirical evidence would be required to fully substantiate this hypothesis. Our specific focus on the production and management of attrition in Bangalore cannot offer more than a first attempt to approach this complex problem. In our opinion, this is a trail worth following, however, and it would be productive to look further at the fragile and contingent strategies of labour utilisation that arise from the difficulty of articulating different regulatory scenarios within a single organisational structure in other companies and in other economic sectors. As far as the German product company in our sample is concerned, however, it is obvious that neither strategy (reproducing the home base on a smaller scale or adapting to a 'low cost location' like Bangalore) can accurately be described as 'homogenisation'. This case of transnational production between regulatory scenarios has demonstrated that it is not the case that 'everything is becoming the same'.

(C) Nicole Mayer-Ahuja and Patrick Feuerstein, 2008

\section{REFERENCES}

Béret, P., A. Mendez, C. Paraponaris \& N. Richez-Battesti (2003) 'R\&D Personnel and Human Resource Management in Multinational Companies: Between Homogenization and Differentiation', International Journal of Human Resource Management, Vol 14, No 3:449-468 Boes, A. \& M. Schwemmle (eds) (2005) Bangalore statt Böblingen? Offshoring und Internationalisierung im IT-Sektor, Hamburg: VSA

Brenner, N. (1998) 'Global Cities, Glocal States: Global City Formation and State Territorial Restructuring in Contemporary Europe', Review of International Political Economy, Vol 5, No 1:1-37 Dicken, P. (2007) Global Shift. Mapping the Changing Contours of the World Economy, London, Thousand Oaks, New Delhi: Sage

Esping-Andersen, G. (1990) The Three Worlds Of Welfare Capitalism, Princeton: Princeton University Press

Fallick, B., C.A. Fleischman \& J.B. Rebitzer (2005) 'Job-Hopping in Silicon Valley: Some Evidence Concerning the Micro-Foundations of a High-Technology Cluster', Working Paper 432 of the Levy Economics Institute of Bard College

Geppert, M., D. Matten \& K. Williams (2002) 'Global Change Management Approaches in MNCs and Distinct National Trajectories: Britain and Germany Compared’ in M. Geppert, D. Matten \& K. Williams (eds) Challenges for European Management in a Global Context, Basingstoke: Palgrave Macmillan:42-67

Ghosh, A. (2005) 'Public Private or a Private Public? Promised Partnership of the Bangalore Agenda Task Force', Economic and Political Weekly, Vol 19, No 11:4915-4922

Hall, P. \& D. Soskice (eds) (2001) Varieties of Capitalism. The Institutional Foundations of Comparative Advantage, Oxford, New York: Oxford University Press

Heeks, R. (1996) India's Software Industry: State Policy, Liberalisation and Industrial Development, Thousand Oaks, London: Sage

Heitzman, J. (2004) Network City. Planning the Information Society in Bangalore, Oxford, New York, New Delhi: Oxford University Press

Hirschfeld, K. (2004) 'Moving East. Relocations of eWork from Europe to Asia' in U. Huws \& J. Flecker (eds) Asian Emergence: the World's Back Office? Brighton: Institute for Employment Studies:27-57

Krishna, A. \& V. Brihmadesam (2006) 'What Does it Take to Become a Software Professional?' Economic \& Political Weekly, Vol 29, No 7:3307-3314

Lateef, A. (1997) 'Linking up with the Global Economy. A Case Study of the Bangalore Software 
Industry', International Institute for Labour Studies, New Industrial Organization Programme, DP/96/1997, accessed on May 2, 2008 from http://www.ilo.org/public/english/bureau/inst/ papers/1997/dp96/index.htm

Lema, R. \& B. Hesbjerg (2003) The Virtual Extension. A Search for Collective Efficiency in the Software Cluster in Bangalore, accessed on May 2, 2008 from http://www.akira.ruc.dk/ rnl/pdf/ The_Virtual_Extension.pdf

Marginson, P., P. Armstrong, P.K. Edwards \& J. Purcell (1995) 'Multinational Companies and the International Management of Labour', The International Journal of Human Resource Management, Vol 6, No 3:702-719

Mayer-Ahuja, N. (2003) Wieder dienen lernen? Vom westdeutschen, Normalarbeitsverhältnis' zu prekärer Beschäftigung seit 1973, Berlin: Edition Sigma

Mayer-Ahuja, N. (2006) 'Normalarbeitsverhältnis in Internetfirmen? Zur Schleichenden Entwertung eines Konzeptes', WSI-Mitteilungen, Vol 6:335-340

Mayer-Ahuja, N. \& P. Feuerstein (2007) 'IT Labour Goes Offshore. Regulating and Managing Attrition in Bangalore', SOFI Working Paper 2, accessed on May 22, 2008 from www.sofigoettingen.de/fileadmin/Textarchiv/SOFI_working_paper_2_2007.pdf

McKinlay, A. (2005) 'Knowledge Management' in S. Ackroyd, R. Batt, P. Thompson \& P.S. Tolbert (eds) The Oxford Handbook of Work \& Organization, Oxford: Oxford University Press:242-262

Mückenberger, U. (1985) 'Die Krise des Normalarbeitsverhältnisses. Hat das Arbeitsrecht noch Zukunft?', Zeitschrift für Sozialreform, Vol 7:415-434, 457-475

Nasscom (2007) Indian IT-Industry. Fact Sheet, accessed on May 2, 2008 from http://www. nasscom.in/upload/5216/Indian_IT_Industry_Factsheet_Feb2007.pdf

Nasscom (2005) 'Feature', in Nasscom Newsline, Issue No 42, accessed on June 19, 2008 from http:// www.nasscom.in/Nasscom/templates/NormalPage.aspx?id=15495

Pries, L. (2005) 'Kräftefelder der Strukturierung und Regulierung von Erwerbsarbeit.

Überlegungen zu einer Entwicklungs- und Institutionenorientierten Sozialwissenschaft der Erwerbsarbeit', SOAPS-Papers 1, accessed on May 2, 2008 from http://www.ruhr-uni-bochum. de/soaps/download/publ-soapspapers1.pdf

Sukumar, R. (2003) 'City in Sync. The Future of Indian Cities is Here. We Have Seen it. And it is Bangalore', Business Today, Delhi, 17.8

Upadhya, C. (2007) 'Employment, Exclusion and "Merit” in the Indian IT-Industry', Economic and Political Weekly, Vol 19, No 5:1863-1868

Upadhya, C. \& A.R. Vasavi (2006) Work, Culture, and Sociality in the Indian IT Industry: A Sociological Study. Final Report, submitted to Indo-Dutch Programme for Alternatives in Development, August 2006, accessed on May 2, 2008 from http://www.union-network.org/ uniindep.nsf/863b5ce2fa055934c1256800002e5ab0/40601d743f5e3567c125723b0034587d/\$FILE/ NIAS-IDPAD\%20IT\%20Study\%20Final\%20Report.pdf

Vogel, M. (2005) 'Einmal Indien und Zurück', CIO, accessed on May 2, 2008 from http://www.cio. de/knowledgecenter/outsourcing/800222/index.html 